\title{
Generation of anti-tumor response by JAWS II mouse dendritic cells transduced with murine interleukin 12 genes
}

\author{
ELZBIETA PAJTASZ-PIASECKA, JOANNA ROSSOWSKA, ANNA SZYDA, \\ AGNIESZKA KRAWCZENKO and DANUTA DUS
}

\begin{abstract}
Ludwik Hirszfeld Institute of Immunology and Experimental Therapy, Polish Academy of Sciences, Wroclaw, Poland
\end{abstract}
Received December 28, 2006; Accepted January 29, 2007

\begin{abstract}
Murine dendritic cells (DCs) of the established JAWS II cell line were transduced with a retroviral vector carrying murine interleukin 12 (IL-12) genes (JAWS II/IL-12 cells). The JAWS II/IL-12 cells produced $~ 9-18$ ng IL-12 protein $/ \mathrm{ml} / 5 \times 10^{5}$ cells $/ 48 \mathrm{~h}$ and displayed an increased CD80 and CD86 expression as well as major histocompatibility complex antigen up-regulation. The JAWS II/IL-12 cells were used as a temporary source of IL-12 for the immunotherapy of C57BL/6 mice bearing transplantable murine colon carcinoma (MC38). The cell vaccines were administered according to different application schedules into the vicinity of subcutaneously growing palpable MC38 tumors. The JAWS II/IL-12 cells were delivered alone or in combination with JAWS II cells pulsed with MC38 tumor cell lysate (TAg) (JAWS II/TAg cells). The anti-tumor response was estimated as the tumor growth delay - the time (days) required for the tumor to reach a volume of $1 \mathrm{~cm}^{3}$ (TRV), and as the increase in animal life-span (ILS). Mice treated with three consecutive injections of JAWS II/IL-12 or JAWS II/TAg cells responded with moderate tumor growth delay (up to 6.5 and 9.5 days, respectively). After the administration of the JAWS II/IL-12 and JAWS II/TAg cell combination, the TRV was prolonged up to 12.5 days and there was a long-lasting tumor growth delay. Increasing the number of DC-based vaccines to four, resulted in the ILS extension of up to $87 \%$ over the control. A similar effect was observed when the vaccine containing the combination of both DC components was delivered prior to the three consecutive injections of JAWS II/IL-12 or
\end{abstract}

Correspondence to: Dr E. Pajtasz-Piasecka, Institute of Immunology and Experimental Therapy PAS, Laboratory of Experimental Anticancer Therapy, R. Weigla st. 12, 53-114 Wroclaw, Poland E-mail: pajtasz@iitd.pan.wroc.pl

Abbreviations: MC38, murine colon carcinoma; MHC, major histocompatibility complex; IL-12, interleukin 12; FACS, fluorescenceactivated cell sorter; ILS, increase in life-span; TGI, tumor growth inhibition; DCs, dendritic cells

Key words: mouse murine colon carcinoma, interleukin 12 genes transduced JAWS II mouse dendritic cells, T cell cytotoxicity , IFN- $\gamma$ production
JAWS II/TAg cells administered independently. The JAWS II/IL-12 cell vaccination of MC38 tumor-bearing mice was accompanied by an increased percentage of IFN- $\gamma$-producing CD8 ${ }^{+}$spleen cells. Concluding, JAWS II DCs transduced with IL-12 genes could be used as an adjuvant vaccine for immuno- as well as combined immuno-chemotherapy of experimental tumors.

\section{Introduction}

Interleukin 12 (IL-12) belongs to the cytokines promoting the development of the Th1 type immune response, which includes Th1 cell stimulation to IFN- $\gamma$ production and memory cell formation as well as the stimulation of CTL and NK cells to cytotoxicity and IFN- $\gamma$ production. It also participates in the modulation of other immunological functions, such as the upregulation of the major histocompatibility complex (MHC) expression level on the surface of antigen-presenting cells, the indirect stimulation of macrophages to nitric oxide production, and involvement in the anti-angiogenesis process by expressing secondary cytokines such as the IFN- $\gamma$-inducible protein 10 (IP-10) (1-3). These IL-12 properties were the main reasons for the attempts to apply IL-12 in anti-tumor immunotherapy. In tumor-bearing individuals, the IL-12 production level depends on the actual balance between the host immune system and the growing tumor. However, native cytokine action alone is usually insufficient for effective antitumor response, and its systemic application, limited to a few human trials, resulted in high toxicity and strong side-effects. Since IL-12 acts in a paracrine manner, consumed locally at the site of immune reaction, its local delivery is a more rational approach. Therefore, an effective expression of IL-12 genes introduced into the tumor or immune effector cells which could be applied locally as an adjuvant cell vaccine could be considered as a therapeutic strategy (4-7).

Dendritic cells (DCs), play an essential role in the initiation of the specific immune response, including antigen-specific CTL response and anti-tumor immunity (8). It has been demonstrated that treating tumor-bearing animals with DCs pulsed with tumor lysate resulted in tumor growth inhibition (TGI) or even in the complete eradication of established tumors. Thus, in a variety of animal tumor models as well as in a few clinical trials, tumor antigen activated DCs have been used as an adjuvant for effective anti-tumor immunization (9-16). Since antigen presentation by DCs is associated with IL-12 
production, stimulation of the anti-tumor immune response by DCs is largely determined by their ability to produce IL- 12 . Therefore, the administration into the tumor site of genetically modified DCs, which can either produce IL-12 alone or are supported by additional cytokine or costimulatory molecules, triggered effective tumor-specific CTL activity and promoted tumor rejection in different experimental mouse tumor models $(3,5,12,17-22)$. After these publications, genetically modified DCs began to be widely investigated as a promising tool for tumor immunotherapy.

In our previous studies we found that transplantable murine colon carcinoma (MC38) responded to immunotherapy with IL-2-secreting allotypic X63mIL-2 plasmocytoma cells. After multiple administrations of IL-2-transfected cells, tumor growth delay or even complete tumor regression were observed (23-25). In the present experimental immunotherapy model, murine DCs of the established JAWS II cell line (ATCC CRL-11904) were transduced with a retroviral vector carrying murine IL-12 genes and further administered in the form of a vaccine serving as a temporary cytokine source. The aim of this study was to measure the effects of JAWS II/IL-12 cells administered by different application schedules on host response against MC38. JAWS II transductants secreting IL-12 induced effective anti-tumor response especially when supported by tumor cell lysate (TAg) pulsed DCs. The multiple vaccines of the JAWS II/IL-12 and JAWS II/TAg cell combination, were the most effective and resulted in long-lasting tumor growth delay as well as a slight increase in the percentage of $\mathrm{CD}^{+} \mathrm{IFN}-\gamma^{+}$spleen cells.

\section{Materials and methods}

Construction of retrovirus-based plasmids. Enhanced green fluorescent protein (EGFP) cDNA was derived from a pEGFP promoter reporter vector (Clontech, USA). Mouse IL-12 cDNA (p35 and p40) was derived from the pEM12 plasmid. The fragments, p35 and p40, were obtained by enzyme digestion: Hind III-Xho I for p35 and Not I-Hind III for p40, respectively. The plasmids, pEM12 and pSAMEN, were kindly provided by Professor R. Hawley, Canada. A detailed description of the retrovirus-based plasmids, pSAMEN EGFP and pSAMEN IL12, was presented in our previous report (26).

Generation of virus packaging cells. The plasmids were introduced into the amphotropic murine PA 317 packaging cell line. The transfection was performed in the presence of Fugene 6 transfection agent (Roche, France) resulting in the amphotropic retroviral packaging cell lines, PA SAM EGFP and PA SAMEN IL-12. Both packaging cell lines were maintained in Dulbecco's modified Eagle's medium (DMEM; Gibco Life Sciences, USA) supplemented with 10\% FCS, glutamine, and antibiotics at $37^{\circ} \mathrm{C}$ in a $5 \% \mathrm{CO}_{2} / 95 \%$ air humidified atmosphere.

Virus-containing supernatant collection. Mouse packaging cell lines were cultured in $10 \%$ FCS DMEM in $25-\mathrm{cm}^{2}$ culture flacks. After reaching full culture confluence, the medium was replaced by Opti-MEM (Gibco Life Sciences) supplemented with 5\% FCS, glutamine, and antibiotics and the cells were incubated for $24 \mathrm{~h}$. The supernatants were collected and centrifuged three times (1000 rpm, 10 min, RT). The retroviral vector titer was determined on MC38 cells by the end-point dilution method (27). Supernatants containing $10^{4} \mathrm{CFU} / \mathrm{ml}$ were used for the DC transduction experiments.

Culture and transduction of JAWS II dendritic cells with retroviral vectors. The C57BL/6 mouse, bone marrow-derived DCs of the JAWS II line (ATCC Cat. No. CRL-11904, USA) were maintained in a 1:1 mixture of alpha MEM and RPMI1640 media supplemented with L-glutamine, antibiotics, and $10 \%$ FCS [complete medium (CM)] containing $5 \mathrm{ng} / \mathrm{ml} \mathrm{GM-}$ $\mathrm{CSF}$ (at $37^{\circ} \mathrm{C}$ in a $5 \% \mathrm{CO}_{2} / 95 \%$ air humidified atmosphere). JAWS II cells were transduced with the supernatant collected from PA SAM EGFP (JAWS II/EGFP cells) as well as from PA SAMEN IL12 (JAWS II/IL-12 cells) packaging cells. The cells were incubated with virus-containing supernatant $\left(10^{4} \mathrm{CFU} / \mathrm{ml}\right)$ diluted 1:2 - 1:3 in CM with $10 \%$ FCS, supplemented with $5 \mathrm{ng} / \mathrm{ml} \mathrm{GM-CSF}$ and $8 \mu \mathrm{g} / \mathrm{ml}$ polybrene for $24 \mathrm{~h}$. In the case of JAWS II/EGFP cells, the transduction was followed by drug selection in the presence of $1.5 \mathrm{mg} / \mathrm{ml}$ geneticin (G418, Sigma, Germany) for 14 days. The ability of the JAWS II/IL-12 cells to produce IL-12 was tested without geneticin selection.

Semi-quantitative reverse transcriptase polymerase chain reaction $(R T-P C R)$. Total RNA was isolated from $\sim 5 \times 10^{6}$ cells using the RNeasy Protect Mini Kit (Qiagen, Germany). The cDNA synthesis was carried out with Omniscript Reverse Transcriptase (Qiagen) at $37^{\circ} \mathrm{C}$ for $1 \mathrm{~h}$. After cDNA synthesis, the transcripts were amplified with mHPRT (240 bp) and mIL-12 gene (700 bp) specific primers: mHPRTs, 5' GCTGGTGAAAAGGACCTCT 3'; mHPRTa, 5' CACAGG ACTAGAACACCTGC 3'; mIL12s, 5' TCCCTGCAGGGTC CGATCCT 3'; mIL12a, 5' GAGGAGGTAGCGTGATTGA CACAT $3 '$.

The PCR reaction parameters for IL-12 were $95^{\circ} \mathrm{C}$ for $2 \mathrm{~min},\left(95^{\circ} \mathrm{C}\right.$ for $30 \mathrm{sec}, 51^{\circ} \mathrm{C}$ for $30 \mathrm{sec}, 72^{\circ} \mathrm{C}$ for $\left.1 \mathrm{~min}\right) \times 35$ cycles, $72^{\circ} \mathrm{C}$ for $5 \mathrm{~min}, 4^{\circ} \mathrm{C}$. For HPRT the reaction parameters were $95^{\circ} \mathrm{C}$ for $5 \mathrm{~min},\left(95^{\circ} \mathrm{C}\right.$ for $30 \mathrm{sec}, 55^{\circ} \mathrm{C}$ for $30 \mathrm{sec}$, $72^{\circ} \mathrm{C}$ for $\left.1 \mathrm{~min}\right) \mathrm{x} 30$ cycles, $72^{\circ} \mathrm{C}$ for $5 \mathrm{~min}, 4^{\circ} \mathrm{C}$. PCR was performed in a thermal cycler (Whatman Biometra, Germany). PCR products were separated by electrophoresis on $1 \%$ agarose gels and visualized under UV light after ethidium bromide staining.

Estimation of IL-12 production. JAWS II/IL-12 cells were settled on 24 -well TC plates $\left(5 \times 10^{5}\right.$ cells $/$ well $\left./ \mathrm{ml}\right)$ in $\mathrm{CM} \pm$ GM-CSF. The cells were cultured for $48 \mathrm{~h}$. Then the supernatants were harvested, centrifuged and frozen at $-20^{\circ} \mathrm{C}$. IL-12 activity was estimated by ELISA (Becton-Dickinson).

Preparation of MC38/0 TAg. The MC38 tumor cells (5x106/ml) were collected, washed two times with $\mathrm{PBS}^{-\mathrm{Ca} \mathrm{Mg}}\left(\mathrm{PBS}^{(-)}\right)$, frozen in liquid nitrogen and thawed $\left(+37^{\circ} \mathrm{C}\right)$, a total of five times. The cell debris was then sonificated for $2 \mathrm{~h}$. The lysate was used for control spleen cell activation, or for JAWS II cell 'pulsation' (antigenic stimulation).

Procedure of JAWS II cell pulsation. JAWS II cells were maintained in $24-w e l l ~ T C$ plates $\left(0.25 \times 10^{6}\right.$ cells $\left./ \mathrm{ml}\right)$ or in $75-\mathrm{cm}^{2}$ 
Table I. Antibodies used for JAWS II DC characteristics.

\begin{tabular}{llll}
\hline Antibody & \multicolumn{1}{c}{ Clone } & Dilution used & Company \\
\hline Rat anti-mouse FITC-conjugated & R-240 & $1 / 100 ; 1 / 400$ & BD Pharmingen \\
H-2K $D^{b}$ & $28-8-6$ & $1 / 100$ & BD Pharmingen \\
I-A & AF6-120.1 & $1 / 100$ & BD Pharmingen \\
(Fab') goat anti-rat FITC-conjugated & & $1 / 100$ & Serotec \\
CD54 rat anti-mouse & KAT-1 & $1 / 1000$ & Serotec \\
CD11b RPE-conjugated & MI/70.15 & $1 / 20$ & Serotec \\
CD11c RPE-conjugated & HL3 & $1 / 40$ & BD Pharmingen \\
Isotype IgG2a & LO-DNP-16 & $1 / 20$ & Serotec \\
CD80 RPE-conjugated & RMMP-1 & $1 / 20$ & Serotec \\
Isotype IgG 1K & R3-34 & $1 / 200$ & BD Pharmingen \\
CD40 RPE-conjugated & $3 / 23$ & $1 / 200$ & BD Pharmingen \\
CD86 RPE-conjugated & GL1 & $1 / 200$ & BD Pharmingen \\
\hline
\end{tabular}

bottles $\left(0.5 \times 10^{6}\right.$ cells $\left./ \mathrm{ml}\right)$ in CM supplemented with $5 \mathrm{ng} / \mathrm{ml}$ GM-CSF for $24 \mathrm{~h}$, then incubated with $10 \% \mathrm{TAg}$ (vol suspension) for the next $24 \mathrm{~h}$. Pulsed JAWS II/TAg cells were collected, washed in $\left.\operatorname{PBS}{ }^{(}\right)$, and resuspended to obtain the required density.

Flow cytometry analysis. JAWS II cells were harvested using $0.2 \%$ EDTA, washed and suspended in $\mathrm{PBS}^{(-)}$containing $2.5 \%$ FCS at a density of $10^{6}$ cells $/ \mathrm{ml}$. For direct immunofluorescence cell staining, the following antibodies were used: RPE-conjugated rat anti-mouse CD80, CD86, CD40, CD11b, and RPE-conjugated hamster anti-mouse CD11c, (Table I). Fifty microliters of the cell suspension were mixed with $50 \mu 1$ properly diluted antibodies and incubated at $4^{\circ} \mathrm{C}$ for $45 \mathrm{~min}$. For indirect cell staining, $50 \mu 1$ cell suspension were incubated with an equal volume of unconjugated mouse anti-mouse $\mathrm{H}-2 \mathrm{~b}$ and $\mathrm{I}-\mathrm{a}$ or rat anti-mouse CD54 antibodies for $30 \mathrm{~min}$ at $4^{\circ} \mathrm{C}$, washed and incubated $\left(4^{\circ} \mathrm{C}\right.$ for $\left.45 \mathrm{~min}\right)$ with FITC-conjugated rat anti-mouse or FITC-conjugated $\mathrm{F}(\mathrm{ab}) 2$ goat anti-rat, respectively. Dead cells were excluded after staining with propidium iodide $(25 \mu \mathrm{g} / \mathrm{ml})$. The analysis was carried out using a Becton-Dickinson FACSCalibur apparatus with Cell Quest Software.

Cell-mediated cytotoxic assay. Splenocytes from naive, untreated or DC-vaccine-treated tumor-bearing mice were isolated, frozen and co-cultured for 5 days with mitomycin C-treated $(50 \mu \mathrm{g} / \mathrm{ml} / 30 \mathrm{~min}) \mathrm{MC} 38$ (MC38/0) cells. The X63mIL-2 plasmacytoma cell supernatant $\left(1 \times 10^{6} / \mathrm{ml} / 72 \mathrm{~h}\right)$ was used in a concentration of $3 \%$ as a source of murine IL-2 for splenocyte activation. Next, the splenocytes were incubated with target MC38/0 cells labeled with $\operatorname{DiOC}_{18}(3)$ (Molecular Probes, USA, $30 \mathrm{~min} / 37^{\circ} \mathrm{C}$ ) at a cell ratio of $10: 1$, and then washed. After four hours of mixed culture of the tumoral target and effector cells, the cells were washed and dead cells were stained with propidium iodide for $5 \mathrm{~min}$ (PI $3.75 \mathrm{mM}$ ). The samples were analyzed by flow cytometry with respect to the FL1 and FL3 channels of fluorescence. The cytotoxicity of the spleen cells was calculated as the percentage of dead cells (PI-positive) among the $\mathrm{DiOC}_{18}(3)$ labeled MC38/0 cells.

$I F N-\gamma$ secretion assay. The test was performed with the use of a MACS Miltenyi Biotec set (Mouse IFN- $\gamma$ Secretion Assay). Splenocytes were harvested from naive, untreated and DC-vaccine-treated tumor-bearing mice and frozen prior to their use. Then they were co-cultured for five days with mitomycin C-treated (50 $\mu \mathrm{g} / \mathrm{ml}$ for $30 \mathrm{~min}) \mathrm{MC} 38 / 0$ cells. Next, the spleen cells $\left(0.5-0.8 \times 10^{6}\right)$ were washed in $2 \mathrm{ml}$ cold buffer $\left(\mathrm{PBS}^{(}()+2 \mathrm{mM}\right.$ EDTA $+0.5 \%$ FCS $)$ and suspended in $90 \mu 15 \%$ CM. To detect IFN- $\gamma$-secreting cells, the cells were labeled with Catch Reagent anti-IFN- $\gamma$ antibody (10 $\mu \mathrm{l}$, rat anti-rat IgG1a) conjugated with rat antibody ( $\mathrm{IgGb}$ ), for $5 \mathrm{~min}$ on ice and incubated for $45 \mathrm{~min}$ at $37^{\circ} \mathrm{C}$ to allow cytokine secretion. Then they were labeled with mouse PE-IFN- $\gamma$ detecting antibody for $10 \mathrm{~min}$ on ice. The cells were additionally counterstained with FITC-conjugated monoclonal antiCD8 antibody and analyzed by flow cytometry. The control spleen cells were maintained in medium supplemented with IL-2 only.

Mouse and tumor system and DC-vaccine treatment schedule. The in vivo experiments were accepted by the Local Ethics Committee for Animal Experiments. The C57BL/6 mice were inoculated subcutaneously (s.c.) with MC38/0 cells $\left(1 \times 10^{6} / 0.2 \mathrm{ml} / \mathrm{mouse}\right)$. Approximately 14 days after tumor inoculation, when the tumors were ca. $40 \mathrm{~mm}^{3}$ in volume, the mice were randomly divided into groups of four to six with similar tumor volumes. The mice were injected 3-4 times peritumorally (p.t.) with JAWS II/IL-12 cells $\left(0.25-1.5 \times 10^{6}\right.$ / mouse, once a week) alone or together with JAWS II/TAg cells. The control mice were given $0.2 \mathrm{ml}$ physiological saline. The vaccinated mice were monitored twice a week, and the tumor volume was estimated by measuring the tumor size and calculated using the formula $1 / 2 \mathrm{a} \mathrm{x} \mathrm{b}^{2}$, where ' $\mathrm{a}$ ' represents the largest diameter and ' $b$ ' the smallest tumor diameter. The time required for the tumor to reach a volume of $1 \mathrm{~cm}^{3}$ (TRV, days) was evaluated graphically, from median tumor growth 


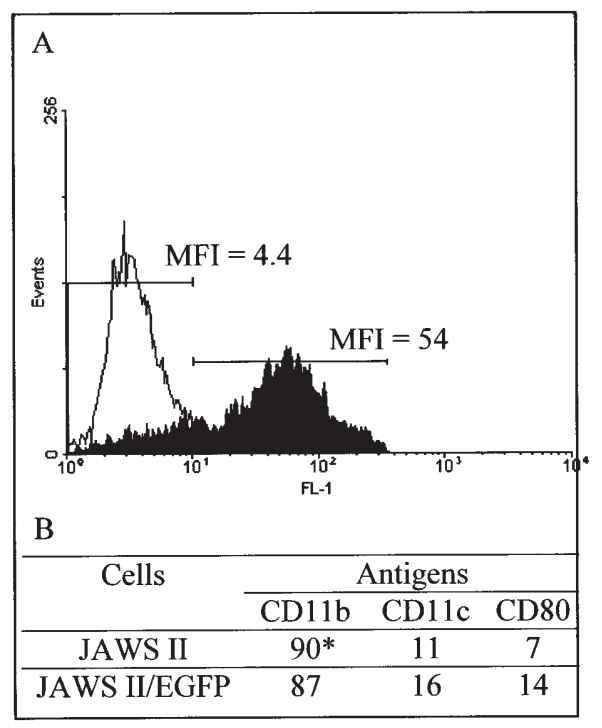

Figure 1. Phenotypic characteristics of mouse JAWS II dendritic cells transduced with the enhanced green fluorescent protein (EGFP) gene (JAWS II/ EGFP cells): The cells were infected with supernatant containing the vector, PA SAM EGFP, $\left(10^{4} \mathrm{CFU} / \mathrm{ml}\right)$. After a number of selections with G418, $81.26 \%$ of strongly EGFP-positive cells were obtained. The fluorescence intensity is expressed as the mean geometric channel of the mean fluorescence intensity (MFI). (A) EGFP expression in the JAWS II/EGFP cells (shadowed histogram), compared with the control JAWS II cells (empty histogram). (B) Flow cytometric phenotypic analysis of the JAWS II/EGFP cells ( ${ }^{*}$ percentage of positive cells).

curves. TGI (\%) was calculated according to the formula 100 - (MVT/MVC x 100) (\%), where MTV represents the median tumor volume in the treated mice and MVC the median tumor volume in the control mice. The anti-tumoral effect was estimated as the increase in life-span (ILS, \%) according to the formula (MST/MSC x 100) - 100 (\%), where MST represents the median survival time of the treated mice and MSC the median survival time of the control mice.

Statistical methods. Statistical differences in TGI were calculated 3-8 days after the third injection, using the KruskalWallis test. The relationship between two particular groups was calculated using the Mann-Whitney U test. Differences with a $p$-value of $p<0.05$ were regarded as significant. Mouse survival was analyzed using the Kaplan-Meier survival test for nonparametric groups. Differences of $p<0.05$ between the groups were regarded as significant.

\section{Results}

JAWS II dendritic cells transduction with EGFP gene. The retroviral plasmid, pSAM EGFP, carrying the green fluorescent protein gene was used as the control of the transduction process. After geneticin (G418) selection, a subline of the JAWS II/ EGFP cells, was obtained (Fig. 1). The efficiency of the JAWS II cell transduction with the pSAM EGFP vector was evaluated by flow cytometry (Fig. 1A). A population of $81.26 \%$ of the transduced cells exhibited a high level of EGFP expression compared with the nontransduced control cells [a mean fluorescence intensity (MFI) of 54 vs 4, respectively). Comparative flow cytometric analysis of the surface phenotype of the nontransduced JAWS II and JAWS II/EGFP cells revealed

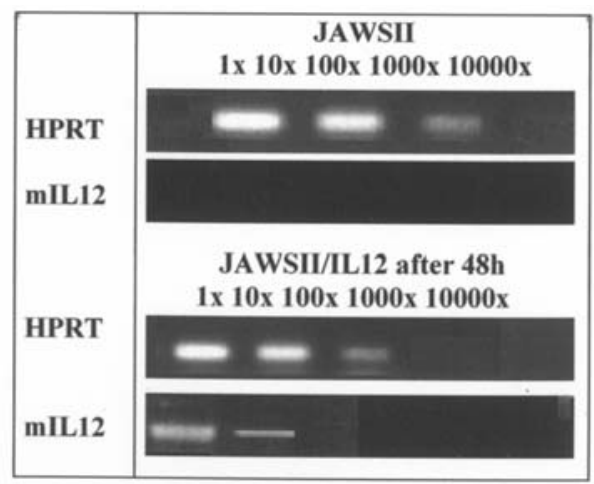

Figure 2. The integration of mouse IL-12 mRNA in transduced JAWS II cells was analyzed by semi-quantitative reverse transcriptase polymerase chain reaction (RT-PCR). The mouse HPRT product was chosen as an internal standard. PCR products were separated by electrophoresis on $1 \%$ agarose gels and visualized under UV light after ethidium bromide staining.

no significant changes between both cell types in the CD11bpositive JAWS II/EGFP cells (90\% vs $87 \%$ ). However, slight increases were noticed in the $\mathrm{CD} 11 \mathrm{c}^{+}$(from 11 to $16 \%$ ), and CD80+ JAWS II/EGFP cells (from 7 to 14\%) (Fig. 1B). Considering these minor differences in the surface antigen expression of the EGFP-producing cells, no significant enhancement of tumor antigen presentation nor immunity generation by these cells were expected compared with the control, nontransduced JAWS II cells.

JAWS II DC transduction with murine IL-12 genes. JAWS II cells were transduced with the retroviral vector SAMEN IL-12, carrying murine IL-12 genes. The IL-12 transgene expression level was analyzed by semi-quantitative RT-PCR using the HPRT gene product as an internal standard (Fig. 2). IL-12transduced JAWS II/IL-12 cells expressed a moderate level of IL-12 mRNA.

The estimation of IL-12 protein production was performed by ELISA. The IL-12 production level was less dependent on the presence of GM-CSF in the culture, than on the time of incubation with the retroviral vector (from 24 up to $48 \mathrm{~h}$ ) and decreased abruptly after an extension of the incubation time. Consequently, JAWS II/IL-12 cells - subjected to 24-h transduction were then cultured $\left(5 \times 10^{5}\right.$ cells $\left./ \mathrm{ml}\right)$ for $48 \mathrm{~h}$ for the collection of supernatants containing IL-12. At these conditions, JAWS II/IL-12 cells produced IL-12 at the level range of $9-18 \mathrm{ng} / \mathrm{ml} / 5 \times 10^{5}$ cells.

The cell surface phenotype of IL-12-producing JAWS II/ IL-12 cells was analyzed by flow cytometry. The transductants were analyzed directly after incubation with the viral vector, and after 24 and $48 \mathrm{~h}$ of cultivation, they revealed significant changes in the JAWS II/IL-12 cells compared with the wild-type JAWS II cells. This caused increases in the percentages of the $\mathrm{CD} 11 \mathrm{c}^{+}(13 \%$ vs $8.5 \%), \mathrm{CD} 80^{+}(27 \%$ vs $17 \%$ ) and $\mathrm{CD}^{2} 6^{+}$cells (59\% vs $33 \%$ ). Only a slight upregulation of MHC class I ( $88 \%$ vs $77 \%)$ and class II $(14 \%$ vs $10 \%$ ) antigens was observed. The percentage of genetically modified cells which acquired maturation markers increased significantly during the first $24 \mathrm{~h}$ of culture after removing the transducing factor (Table II). The effect was similar to that obtained after the JAWS II cell stimulation with known 
Table II. Phenotypic characteristics of transduced JAWS II DCs used as a vaccine.

\begin{tabular}{|c|c|c|c|c|c|}
\hline Cells & CD80 & CD86 & CD54 & $\mathrm{H}-2$ & $\mathrm{I}-\mathrm{a}$ \\
\hline \multicolumn{6}{|c|}{ Directly after transduction ${ }^{\mathrm{a}}$} \\
\hline JAWS II-control & 17 & 31 & 97 & 87 & 10 \\
\hline JAWS II/TAgb & 33 & 48 & 99 & 90 & 14 \\
\hline JAWS II/IL-12 & 39 & 70 & 98 & 90 & 17 \\
\hline \multicolumn{6}{|c|}{ 24-h Culture after transduction } \\
\hline JAWS II-control & 16 & 45 & 98 & 95 & 29 \\
\hline JAWS II/IL-12 & 33 & 80 & 98 & 97 & 23 \\
\hline \multicolumn{6}{|c|}{ 48-h Culture after transduction } \\
\hline JAWS II-control & 25 & 30 & 99 & 92 & 12 \\
\hline JAWS II/IL-12 & 33 & 69 & 99 & 97 & 7 \\
\hline
\end{tabular}

${ }^{a}$ After 24-h incubation with the viral vector; ${ }^{b}$ after 24-h incubation with the tumor lysate (performed simultaneously with viral infection). JAWS II cells were suspended in PBS containing 2.5\% FCS at a density of $10^{6}$ cells $/ \mathrm{ml}$. The CD80 and CD86 expressions were examined by flow cytometry using fluorochrom-labeled antibodies. MHC molecules and CD54 expression were analyzed after indirect cell staining. Analysis was carried out using a Becton-Dickinson FACSCalibur apparatus with Cell Quest Software.

activators of DC maturation (LPS, IFN- $\gamma$ or IL-12) as well as - but to a lesser extent, with TAg (Table II).

The use of JAWS II/IL-12 cells as a DC-based vaccine for immunotherapy of mice with established MC38 tumors. C57BL/6 mice were inoculated subcutaneously (s.c) with MC38 cells. After 14 (13-15) days, when the tumors became palpable, the mice were injected peritumorally (p.t.) with JAWS II/IL-12 or tumor antigen-pulsed (JAWS II/TAg) cells or with their combination (JAWS II/IL-12 and JAWS II/TAg cells). JAWS II cells were administered for three (Fig. 3A and B) or four (Fig. 3C) consecutive weeks. The control animals received $\sim 1 \times 10^{6}$ of the JAWS II/EGFP cells alone or in combination with the JAWS II/TAg cells (cell ratio, 1:2). The administration of JAWS II/EGFP cells did not affect the tumor growth delay (Fig 3A) (Table III). However, if they were given together with JAWS II/TAg cells, a tumor growth delay was observed. The difference in time required for the tumor to reach a volume of $1 \mathrm{~cm}^{3}(\Delta \mathrm{TRV})$ was extended by about 4.5 days $(\mathrm{p}<0.05)$. The injection of JAWS II/IL-12 cells alone resulted in slight tumor growth suppression ( $\triangle \mathrm{TRV}, 2$ days). However, the administration of JAWS II/ IL-12 in combination with JAWS II/ TAg cells significantly delayed tumor growth $(\triangle \mathrm{TRV}, 12$ days). Mice which received three vaccinations of JAWS II/ IL-12 cells, showed a $40 \%$ TGI, whereas the animals which obtained the combined vaccine, showed up to a $78 \%$ TGI. In the other experiment (Fig 3B) (Table III), mice were vaccinated with a number of cells lower than in the previous experiment $\left(0.7-1.1 \times 10^{6} /\right.$ per injection). In this case the administration of JAWS II/IL-12 or JAWS II/TAg cells alone, resulted in a $\triangle \mathrm{TRV}$ increase of up to 6.5 days, and the application of vaccines causing the combination of both cell types resulted in a $\Delta T R V$ increase of up to 12 days. The differences between the volumes calculated on the 35 th day ( 7 days after the third vaccination) proved to be statistically significant $(\mathrm{p}<0.01)$ compared with the control. A more sophisticated schedule of DC-vaccine application was conducted in the next experiment (Fig 3C) (Table III). First, all the mice were vaccinated with a combination of JAWS II/IL-12 and JAWS II/TAg cells (1.1x10\% mouse). Then the animals were divided into three groups and administered three consecutive vaccines of JAWS II/IL-12, JAWS II/TAg cells alone or their combination. All together, the mice received four cell vaccines, resulting in an increased $\triangle T R V$ (12.5 days). It should be mentioned that vaccination with the JAWS II/IL-12 and JAWS II/TAg cell combination followed by vaccines containing one type of DCs resulted in no enhancement of TGI compared with the DC combination. However, four-fold JAWS II/IL-12 and JAWS II/TAg cell applications resulted in an ILS of up to $87 \%$ over the control (Table III), which was accompanied by a long-lasting, statistically significant, tumor growth delay (Fig. 3C). The survival of tumor-bearing mice, as estimated by the KaplanMeier test, depended on the number of vaccinations, revealing statistical significance $(\mathrm{p}<0.05)$ only for mice receiving four DC-vaccines (Fig. 4C).

Host immune cell activity. Determination of the cytolytic activity of the spleen cells and the detection of IFN- $\gamma$ secreting spleen cells of mice receiving either JAWS II/TAg or JAWS II/TAg and JAWS II/IL-12 cell vaccines were performed (Fig. 5). Splenocytes were collected after the third DC-vaccination. The control splenocytes were collected from the naïve and tumor-bearing control mice. After five-day TAg restimulation in vitro, the cytotoxicity of the spleen cells was estimated. The comparative analysis did not reveal significant differences in the cytotoxicity of the splenocytes among the experimental and control groups, even in the case of mice with long-lasting tumor growth delay. In order to estimate the percentage of $\mathrm{CD}^{+} \mathrm{IFN}-\gamma$-producing splenocytes, restimulated spleen cells were labeled with an antibody against IFN- $\gamma$ and further counterstained with an antibody against CD8. The percentage of positive cells was calculated and compared with the control spleen cells maintained in medium supplemented with IL-2 only. The vaccination with JAWS II/TAg cells and JAWS II/IL-12 cells resulted in a decrease in the number of $\mathrm{CD}^{+}$splenocytes accompanied by a slight increase in the percentage of IFN- $\gamma$-producing spleen cells, mainly $\mathrm{CD}^{+}$ cells. This phenomenon is associated with the number of injections and is inversely proportional to the tumor volume. It was particularly noticeable in the case of individual animals with a long survival (example in Fig. 5, but overall data not shown). These observations could imply the escape of activated $\mathrm{T}$ cells from peripheral organs, such as the spleen, to the vicinity of the tumor nodule.

\section{Discussion}

Among the different types of cellular vaccines, protocols using DCs pulsed with tumor lysate have proved to be the most promising and simplest way to enhance anti-tumor immunity in mice and even in some humans with advanced 

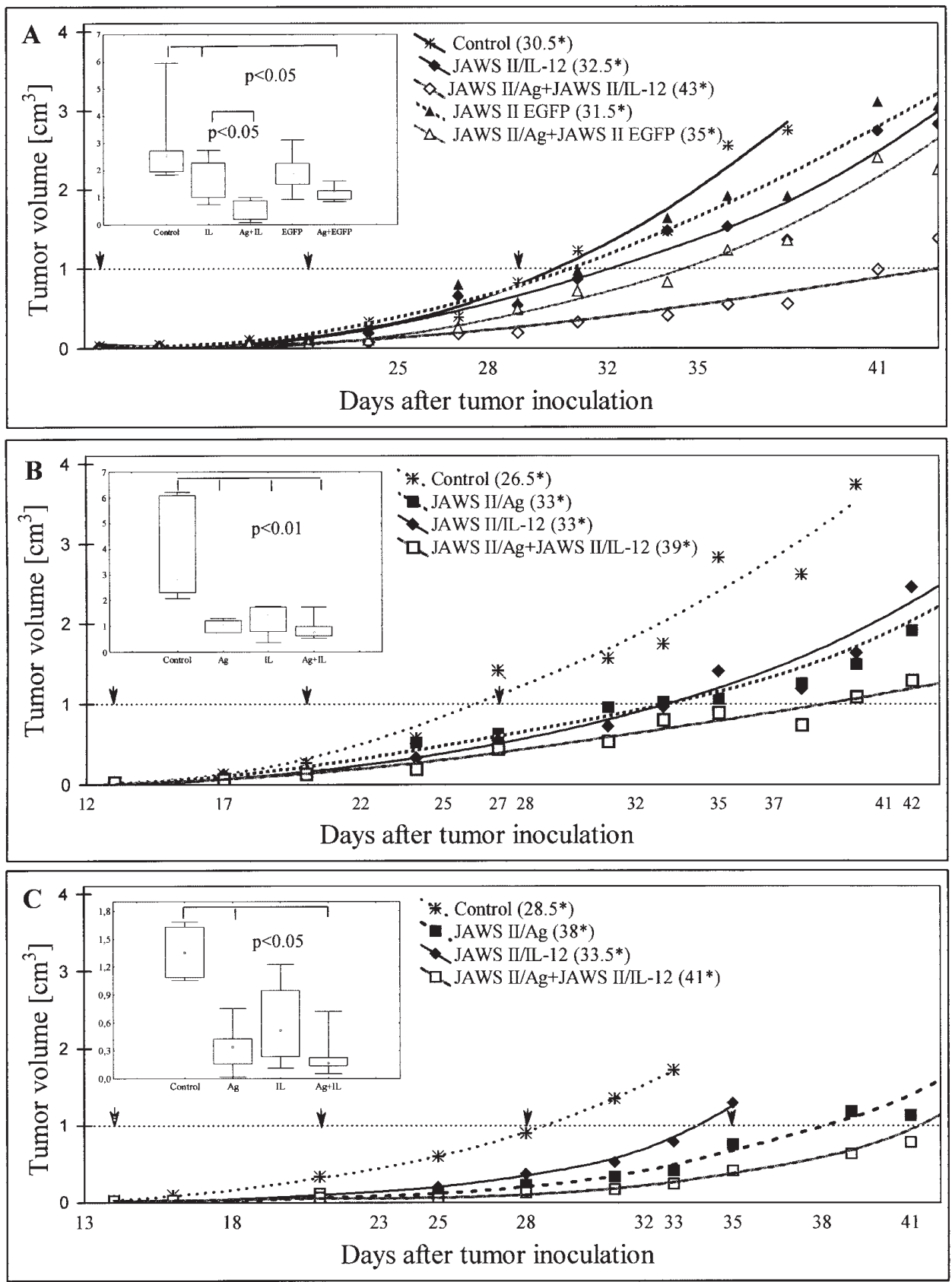

Figure 3. Effects of multiple peritumoral injections of the JAWS II/IL-12 cell vaccine alone or in combination with the JAWS II/tumor cell lysate (TAg) cells on MC38 tumor growth in C57BL/6 mice. Cells were administered for three (A and B) or four (C) consecutive weeks (arrows). * Median time, in days for the tumor to reach a volume of $1 \mathrm{~cm}^{3}$ (TRV). Inserts contain the illustration of the statistical differences between the groups as calculated by the Kruskal-Wallis test 7-8 days (A and B) or 3 days (C) after the 3 rd cell injection. Statistical differences in TGI (expressed as the median tumor volume) were calculated using the Kruskal-Wallis and Mann-Whitney $\mathrm{U}$ tests. Differences where $\mathrm{p}<0.05$ were regarded as significant.

cancer (28). The murine DCs of the established JAWS II cell line are able to prime the activity of spleen cells in vitro $(10,13,29)$. Antigen presentation by DCs, followed by their maturation, has proved to be associated with short-lived IL-12 production. To extend the time of cytokine production, the use of genetically engineered IL-12 secreting cells has been considered. In a variety of animal tumor models, it was demonstrated that the administration of cytokine-producing DCs (including IL-12-producing cells) into the tumor site promoted tumor rejection by enhancing anti-tumor immunity $(5,12,17-19,21,22)$. However, the options of DC delivery have not yet been satisfactorily established.
In the presented study, JAWS II cells transduced with a retroviral vector carrying murine IL-12 genes were used as a short-term cytokine depot to elicit anti-tumor immune response. The JAWS II wild-type cells are characterized by a high expression of MHC class I, CD54 and CD11b antigens and moderate levels of costimulatory molecules such as CD11c or CD80, as well as CD86. Only a small percentage of JAWS II cells express the MHC class II antigen and they are virtually CD40-negative $(13,29,30)$.

First, JAWS II cell transduction with the reporter EGFP gene was performed. The transduction efficiency, followed due to intracytoplasmic EGFP production, was observed in 
Table III. MC38 tumor growth in C57BL/6 mice treated with multiple peritumoral injections of JAWS II/IL-12 cells alone or in combination with JAWS II/TAg cells.

\begin{tabular}{lllll}
\hline Groups & $\begin{array}{c}\text { Number of } \\
\text { injections }\end{array}$ & $\begin{array}{c}\text { TRV } \\
\text { (days) }\end{array}$ & $\begin{array}{c}\Delta \text { TRV } \\
\text { (days) }\end{array}$ & $\begin{array}{c}\text { TGI } \\
(\%)\end{array}$ \\
\end{tabular}

\section{Exp. 1}

Control

JAWS II/EGFP

JAWS II/IL-12

JAWS II/TAg+/JAWS II EGFP

JAWS II/TAg+JAWS II/IL-12

Exp. 2

Control

JAWS II/TAg

JAWS II/IL-12

JAWS II/TAg + JAWS II/IL-12

Exp. 3

Control
JAWS II/TAg
JAWS II//IL-12
JAWS II/TAg + JAWS II/IL-12

3

30.5
31.5
32.5
35
43

3

26.5

33

33

39

4
28.5
38
33.5
41
1

2

4.5

12.5
25.4

40

52

78.5
ILS

$\%)$

$\mathrm{TAg}$, tumor cell lysate; EGFP, enhanced green fluorescent protein; TRV, time in days required for the tumor to reach a volume of $1 \mathrm{~cm}^{3}$; $\triangle T R V$, difference between the TRV of the treated and control mice. TGI was measured according to the formula 100 - (MVT/MVC x 100) (\%), with MTV representing the median tumor volume in the treated mice and MVC the median tumor volume in the control mice. Statistical differences in TGI (measured by the median tumor volume) were calculated after the third injection of every experiment, using the Kruskal-Wallis and Mann-Whitney U tests. Differences of $p<0.05$ were regarded as significant. ILS was measured according to the formula (MST/MSC x 100) - 100 (\%) with MST representing the median survival time for the treated mice and MSC the median survival time for the control mice.

$81.26 \%$ of the transduced cells (Fig. 1). A similar retroviral vector (the pMX) used by Akiyama et al (17) resulted in only about $40 \%$ of positive cells being GFP-transduced demonstrating an increased expression of cell maturity markers. In our study, however, JAWS II/EGFP cells revealed no significant changes in their maturation level. The EGFP-producing cells displayed typical DC behavior after antigen pulsation and underwent maturation without an increase in the EGFP autofluorescence. They were also able to generate host immunity, similar to the untreated JAWS II control cells.

Using the conditions determined for the reporter EGFP vector, JAWS II cells were transduced with the retroviral vector SAMEN IL-12 carrying murine IL-12 genes. The transduced JAWS II/IL-12 cells expressed a moderate level of IL-12 mRNA (Fig. 2), and produced 9-18 ng IL-12/ml $/ 5 \times 10^{5}$ cells. A lower level of IL-12 production was obtained by Melero et al after DC transduction with the use of an adenoviral vector (12), as opposed to the high level of IL-12 production obtained by Akiyama et al (17) using a pMX retroviral vector. The analysis by flow cytometry revealed the most evident differences between the wild-type JAWS II and JAWS II/IL-12 cells. During the first $24 \mathrm{~h}$ of culture after transduction (Table II), the increase in population size of cells expressing maturation markers could be observed. This included a small increase in the percentage of CD11 $\mathrm{c}^{+}$cells, a moderate increase in the percentage of CD80 and CD86-positive cells, and a slight up-regulation of cells positive for both $\mathrm{MHC}$ classes. The maturation process of JAWS II/IL-12 cells was similar to that induced by the stimulation with known DC maturation activators (LPS, IFN- $\gamma$, or IL-12) as well as, but to a lesser extent, with TAg. These data contradict evidence published by Akiyama et al (17) of a significant increase in the percentage of DC transductants expressing the CD11c antigen. The differences could be due to the origin of their engineered DCs which were ex vivo cultured DCs.

Tumor antigens with unknown antigenic characteristics could be produced by repeated freezing and thawing or by the sonification of whole tumor cells (16). In the present study, both JAWS II and JAWS II/EGFP cells were loaded (pulsed) with MC38 tumor lysates. As a result of this stimulation a marked increase in CD11c expression was observed. However, the application of these cells as a vaccine had no significant effect on tumor growth delay (Fig. 3A) (Table III).

In some publications, the local peritumoral administration of IL-12-producing DCs usually resulted in the significant inhibition of the tumor growth $(5,10)$. However, in the model presented here, the administration of JAWS II/IL-12 cells resulted only in an insignificant tumor growth delay. In 

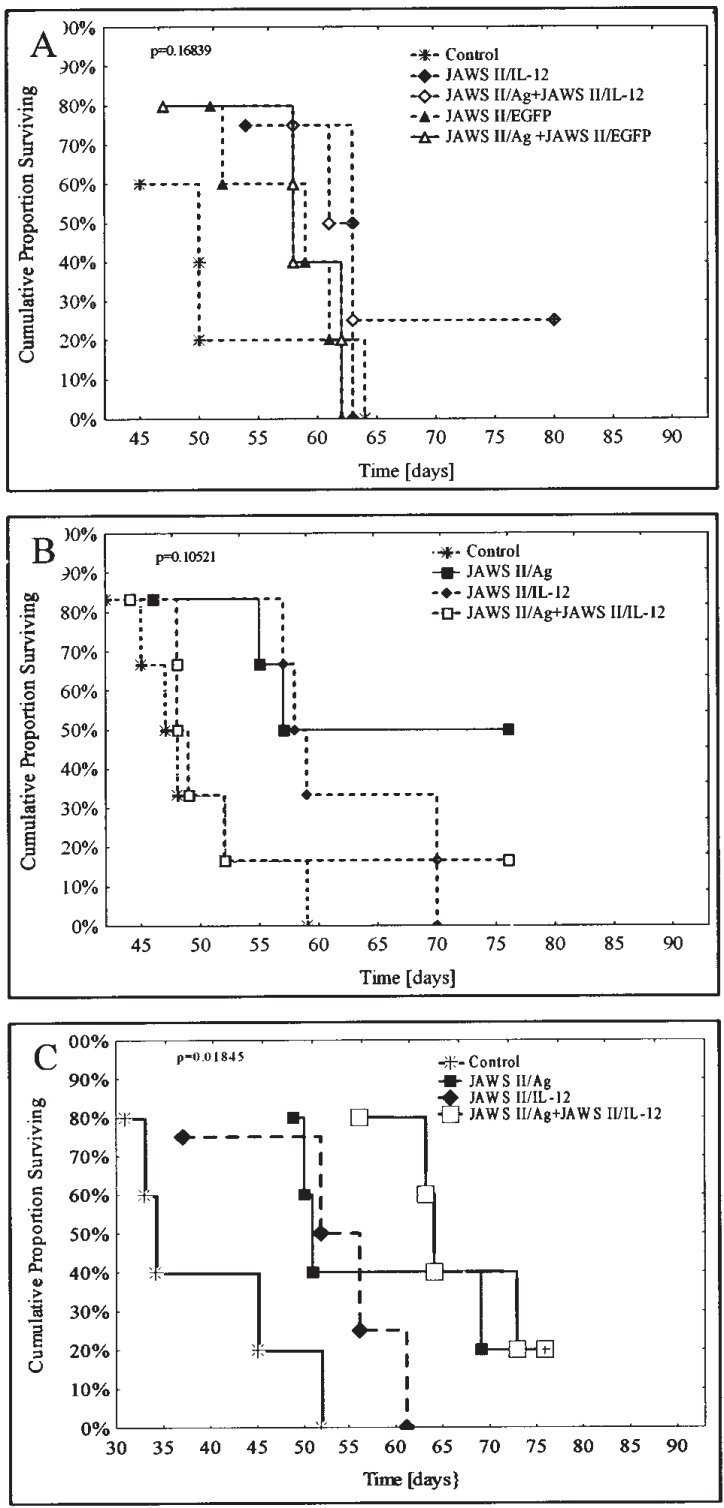

Figure 4. Median survival time of C57BL/6 mice bearing the MC38 tumor, vaccinated with three (A and B) or four $(\mathrm{C})$ peritumoral injections of JAWS II/ IL-12 cells, JAWS II/TAg cells alone or in combination. The Cumulative Proportion Surviving was estimated by the Kaplan-Meier survival test. The differences between the groups were statistically significant $(\mathrm{p}<0.05)$ only after the vaccines were administered four times $(\mathrm{C})$.

contrast, when JAWS II/IL-12 cells were used in combination with JAWS II/TAg cells, a statistically significant tumorinhibitory effect was visible ( $\triangle \mathrm{TVR}$ up to 12 days compared with the control group) (Fig. 3). Furthermore, the changes in TGI in the particular groups calculated 7-8 days after the third vaccination proved to be statistically significant $(\mathrm{p}<0.01)$ compared with the control group. Thus, as it was underlined by Mendoza et al (13), the local concentration of mature DCs inoculated at the tumor site can control the tumor growth. The administration of matured DCs as a necessity for successful anti-tumor immunotherapy was also considered by Schulz et al (33).

The problems of the efficacy of multiple administrations of DCs pulsed with tumor antigens have been considered in some publications (7). The experiments presented here confirm the positive effects of extended vaccine application. When the

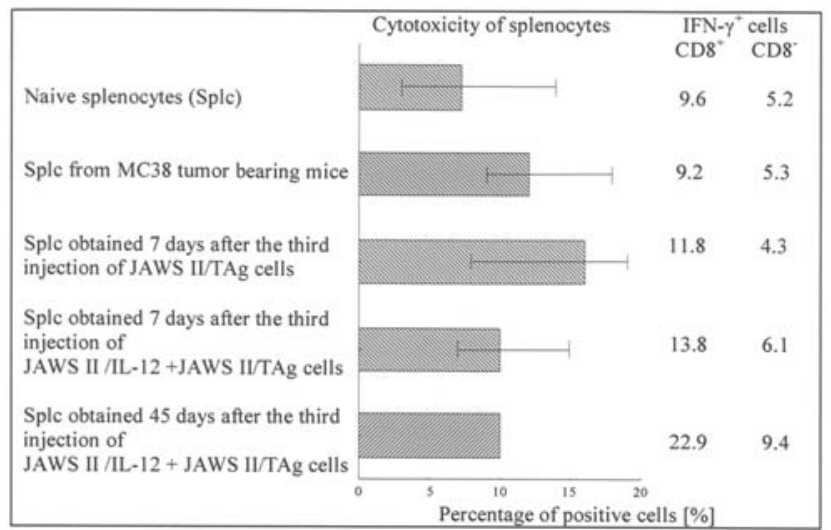

Figure 5. Late activities of immune cells after the injection of JAWS II cellbased vaccines, as estimated by cytotoxic activity and the percentage of IFN- $\gamma$-producing splenocytes. Splenocytes were restimulated for five days with mitomycin C-treated MC38/0 cells in the presence of IL-2. Target MC38/0 cells were stained with $\operatorname{DiOC}_{18}(3)$ for $4 \mathrm{~h}$ and then treated with PI. The cytotoxicity of the spleen cells was analyzed by flow cytometry (Materials and methods).

IL-12 transducted cells were given three times, a significant tumor growth delay was not observed. However, when the animals received four vaccinations, statistically significant differences in survival could be observed between the experimental animal groups ( $\mathrm{p}<0.05$, Fig. $4 \mathrm{C})$.

Since not only T cells, but also NK cells, NKT cells and/ or macrophages could be involved in the IL-12-generated anti-tumor response, this cytokine could also be effective in the therapy of some MHC class I-negative tumors (20). Presumably, the application of a vaccine containing IL-12 transducted cells (i.e. JAWS II/IL-12 cells) contributed to the recovery of various immunological mechanisms of tumor defense, such as cellular immunity (including the immunosensitivity of tumor cells to $\mathrm{CD} 8^{+}$cytotoxic $\mathrm{T}$ lymphocytes). JAWS II/IL-12 and JAWS II/TAg cells differ in their abilities to generate anti-tumor immunity. The slow MC38 tumor growth could be associated with the increased percentage of effector $\mathrm{CD}^{+}$cytotoxic cells able to IFN production. This observation could imply the escape of activated T cells from peripheral organs, such as the spleen, to the vicinity of the tumor nodule to infiltrate tumor tissue.

The important relationship between the IL-12 production level and in vivo DC activity has been considered by other authors who have pointed out the role of this cytokine in the induction of IFN- $\gamma$ and TNF- $\alpha$ production. Tumor regression proved to be associated with a detectable CTL response directed against tumor antigens captured by DCs and particularly by DCs genetically modified to release IL-12 at the tumor site $(5,12,17,31,32)$. Although the activation of mature macrophages with all the consequences of their activity should be considered, host $\mathrm{CD} 8^{+}$cells activated by cross-priming with injected JAWS II cells can produce IFN- $\gamma$ (Fig. 5), which upregulates the expression of MHC class I molecules on the MC38/0 cells, and in this way can help to induce the sensitivity of the MC38/0 tumor to T cell-mediated immunity. The possibility of the in vitro triggering off MHC class I molecule expression on the MC38/0 cell surface by exogenous IFN- $\gamma$ has been described previously (26). Hence, the IL-12-gene- 
modified JAWS II cells temporary secreting IL-12, especially administered together with tumor antigen-activated JAWS II cells, could be considered as a model adjuvant vaccine for immuno- as well as combined immuno-chemotherapy in experimental models. The results presented in this study also open the possibility of the similar treatment of corresponding human malignancies.

\section{Acknowledgements}

This study was supported by the Ministry of Scientific Research and Information Technology (grants PBZ-KBN091/PO5/2003 and 2/P05A/034/27/2004, Poland). We would like to thank Dr Piotr Wysocki, and Professor Andrzej Mackiewicz for the construction of the retroviral vectors and Dr Halina Kusnierczyk for her interest in this work.

\section{References}

1. Colombo MP and Trinchieri G: Interleukin-12 in anti-tumor immunity and immunotherapy. Cytokine Growth Factor Rev 13: 155-168, 2002.

2. Trinchieri G: Interleukin-12: cytokine at the interface of inflammation and immunity. Adv Immunol 70: 83-243, 1998.

3. Trinchieri G: Interleukin-12 and the regulation of innate resistance and adaptive immunity. Nat Rev Immunol 3: 133-146, 2003.

4. Indrová M, Reinis M, Bubeník J, Jandlová T, Bieblová J, Vonka V and Velek J: Immunogenicity of dendritic cell-based HPV16 E6/E7 peptide vaccines: CTL activation and protective effects. Folia Biol (Praha) 50: 184-193, 2004.

5. Huttner KG, Breuer SK, Paul P, Majdic O, Heitger A and Felzmann T: Generation of potent anti-tumor immunity in by interleukin-12-secreting dendritic cells. Cancer Immunol Immunother 54: 67-77, 2005.

6. Lasek W, Feleszko W, Golab J, Stoklosa T, Marczak M, Dabrowska A, Malejczyk M and Jakóbisiak M: Antitumor effects of the combination immunotherapy with interleukin-12 and tumor necrosis factor a in mice. Cancer Immunol Immunother 45: 100-108, 1997.

7. Ribas A, Butterfield LH, Glaspu J and Economou JS: Cancer immunotherapy using gene-modified dendritic cells. Curr Gene Ther 2: 57-78, 2002.

8. Lanzavecchia A and Sallusto F: The instructive role of dendiritic cells on $\mathrm{T}$ cell responses: lineages, plasticity and kinetics. Curr Opin Immunol 13: 291-298, 2001.

9. Gunzer M, Jänich S, Varga G and Grabbe S: Dendritic cells and tumor immunity. Semin Immunol 13: 291-302, 2001.

10. Indrova M, Mendoza L, Reinis M, Vonka V, Smahel M, Nemeckowá S, Jandlowá T and Bubenik J: Bone marrow dendritic cell-based anticancer vaccines. Adv Exp Med Biol 445: 355-358, 2001.

11. Kotera Y, Shimizu K and Mule JJ: Comparative analysis of necrotic and apoptotic tumor cells as a source of antigen(s) in dendritic cell-based immunization. Cancer Res 61: 8105-8109, 2001.

12. Melero I, Duarte M, Ruiz J, Sangro B, Galofre IC, Mazzolini G, Bustos M, Qian C and Prieto J: Intratumoral injection of bonemarrow derived dendritic cells engineered to produce interleukin-12 induces complete regression of established murine transplantable colon adenocarcinomas. Gene Ther 6: 1779-1784, 1999.

13. Mendoza L, Indrova M, Hájková R, Reinis M, Smahel M, Vonka V, Bubenik J and Jandlowá T: Peritumoral administration of antigen-unstimulated bone marrow-derived dendritic cells inhibits tumour growth. Folia Biol (Praha) 46: 91-97, 2000.

14. Nencioni A and Brossart P: Cellular immunotherapy with dendritic cells in cancer: current status. Stem Cells 22: 501-513, 2004.

15. Tatsumi T, Takehara T, Kanto T, Miyagi T, Kuzushita N, Sugimoto Y, Jinushi M, Kasahara A, Sasaki Y, Hori M and Hayashi N: Administration of interleukin-12 enhances the therapeutic efficacy of dendritidc cell-based tumor vaccines in mouse hepatocellular carcinoma. Cancer Res 61: 7563-7567, 2001.
16. Wierecky J, Muller MR, Wirths S, Halder-Oehler E, Dorfel D, Schmidt SM, Hantschel M, Brugger W, Schroder S, Horger MS, Kanz L and Brossart P: Immunologic and clinical responses after vaccinations with peptide-pulsed dendritic cells in metastatic renal cancer patients. Cancer Res 66: 5910-5918, 2006.

17. Akiyama Y, Watanabe M, Maruyama K, Ruscetti FW, Wiltrout RH and Yamaguchi K: Enhancement of antitumor immunity against B16 melanoma tumor using genetically modified dendritic cells to produce cytokines. Gene Ther 7: 2113-2121, 2000.

18. Akiyama Y, Maruyama K, Watanabe M and Yamaguchi K: Retroviral-mediated IL-12 gene transduction into human CD34 ${ }^{+}$ cell-derived dendritic cells. Int J Oncol 21: 509-514, 2002.

19. Gambotto A, Cicinnati VR and Robbins PD: Genetic engineering of dendritic cells. In: Dendritic Cells Biology and Clinical Applications. Lotze MT and Thomson AW (eds). 2nd edition. 2001

20. Indrová M, Bubeník J, Mikysková R, Mendoza L, Símová J, Bieblová J, Jandlová T, Jinoch P, Smahel M, Vonka V and Pajtasz-Piasecka E: Chemoimmunotherapy in mice carrying HPV-16 associated, MHC class I and MHC class I tumours: Effects of CBM-4A potentiated with IL-2, IL-12, GM-CSF and genetically modified tumour vaccines. Int J Oncol 22: 691-695, 2003.

21. Ojima T, Iwahashi M, Nakamura M, Matsuda K, Naka T, Nakamori $M$, Ueda K, Ishida $K$ and Yamaue $H$ : The boosting effect of co-transduction with cytokine genes on cancer vaccine therapy using genetically modified dendritic cells expressing tumor-associated antigen. Int J Oncol 28: 947-953, 2006.

22. Nishioka Y, Hirao M, Robbins PD, Lotze MT and Tahara H: Induction of systemic and therapeutic antitumor immunity using intratumoral injection of dendritic cells genetically modified to express interleukin 12 of systemic and therapeutic antitumor immunity using intratumoral injection of dendritic cells genetically modified to express interleukin 12. Cancer Res 59: 4035-4041, 1999.

23. Kusnierczyk H, Pajtasz-Piasecka E and Radzikowski C: Synergistic antitumour effects of chemo-immunotherapy with an oxazaphosphorine drug and interleukin-2-secreting cells in a mouse colon cancer model. Med Oncol 16: 267-278, 1999.

24. Pajtasz-Piasecka E, Glazman-Kusnierczyk H, Salwa J, Konarski L and Radzikowski C: Growth inhibition of transplantable tumors in mice by mIL-2-secreting murine plasmocytoma cells used alone or in combination with a cytostatic agent. Arch Immunol Ther Exp 43: 281-292, 1995.

25. Pajtasz-Piasecka E, Kusnierczyk H, Krawczyk K, Piasecki E, Elas $\mathrm{M}$ and Radzikowski $\mathrm{C}$ : The effects of peritumoral therapeutic vaccination with IL-2-secreting cells on growth of MC38 colon tumors, local NO production and sentinel lymph node cells activation. Adv Exp Med Biol 495: 385-388, 2001.

26. Pajtasz-Piasecka E, Szyda A, Rossowska J, Krawczenko A, Indrova M, Grabarczyk P, Wysocki P, Mackiewicz A and Dus D: Loss of tumorigenicity of murine colon carcinoma MC 38/0 cell line after transduction with a retroviral vector carrying murine IL-12 genes. Folia Biol (Praha) 50: 7-14, 2004.

27. Szyda A, Pajtasz-Piasecka E, Krawczenko A, Grabarczyk P, Wysocki P, Kozlak J, Paprocka M, Mackiewicz A and Dus D: Mouse colon carcinoma MC38 cell line for rapid and accurate titration of amphotropic retroviral vector. Polish J Environ Studies 14 (Suppl II): 790-794, 2005.

28. Sift 2003, Friedl J, Dubsky P, Bachleitner-Hofmann T, Schueller G, Zontsich T, Benkoe T, Radelbauer K, Brostjan C, Jakesz R and Gnant M: Dendritic cell-based vaccination in solid cancer. J Clin Oncol 21: 135-142, 2003.

29. Brossart P, Goldrath AW, Butz EA, Martin S and Bevan MJ: Virus-mediated delivery of antigenic epitopes into dendritic cells as a means to induce CTL. J Immunol 158: 3270-3276, 1997.

30. Butz EA and Bevan MJ: Differential presentation of the same MHC class I epitopes by fibroblasts and dendritic cells. J Immunol 160: 2139-2144, 1998.

31. Steinman RM and Dhodapkar M: Active immunization against cancer with dendritic cells: the near future. Int J Cancer 94: 459-473, 2001.

32. Ribas A, Wargo JA, Comin-Anduix B, Sanetti S, Schumacher LY, McLean C, Dissette VB, Glaspy JA, McBride WH, Butterfield LH and Economou JS: Enhanced tumor responses to dendritic cells in the absence of CD8-positive cells. J Immunol 172: 4762-4769, 2004.

33. Schulz E, Berger T and Shuler G: Immunotherapy and dendritic cells. Enhancer Biother Cancer 2: 2-7, 2004. 